\title{
Review Article \\ Direct-Acting Antivirals for the Treatment of Chronic Hepatitis C: Open Issues and Future Perspectives
}

\author{
Hee Bok Chae, Seon Mee Park, and Sei Jin Youn \\ Department of Internal Medicine, Chungbuk National University Hospital, Chungbuk National University College of Medicine, \\ 1 Sunwhan-ro, Heungdok-gu, Cheongju 361-711, Republic of Korea
}

Correspondence should be addressed to Hee Bok Chae; hbchae@chungbuk.ac.kr

Received 30 March 2013; Accepted 6 May 2013

Academic Editors: Q. Z. Dong, Y. Hiasa, P. Loyer, and S.-N. Lu

Copyright (C) 2013 Hee Bok Chae et al. This is an open access article distributed under the Creative Commons Attribution License, which permits unrestricted use, distribution, and reproduction in any medium, provided the original work is properly cited.

Currently, two direct-acting antivirals (DAAs) show well-established efficacy against hepatitis C virus (HCV), namely, first-wave protease inhibitors telaprevir and boceprevir. Most clinical trials have examined DAAs in combination with standard of care (SOC) regimens. Future therapeutic drugs were divided into three categories. They are second-wave protease inhibitors, second-generation protease inhibitors, and polymerase inhibitors. Second-wave protease inhibitors are more improved form and can be administered once a day. Oral drug combinations can be favored because interferon (IFN) not only has to be given as intradermal injection, but also can cause several serious side effects. Combination of drugs with different mechanisms shows a good sustained virological response (SVR). But several mutations are associated with viral resistance to DAAs. Therefore, genotypic resistance data may provide insights into strategies aimed at maximizing SVR rates and minimizing resistance. Combined drug regimens are necessary to prevent the emergence of drug-resistant HCV. Many promising DAA candidates have been identified. Of these, a triple regimen containing sofosbuvir shows promise, and treatment with daclatasvir plus asunaprevir yields a high SVR rate (95\%). Oral drug combinations will be standard of care in the near future.

\section{Introduction}

Until now, combined treatment with pegylated interferon$\alpha(\mathrm{PegIFN}-\alpha)$ and ribavirin (RBV) (known as PR therapy) has been the standard of care (SOC) for patients chronically infected with hepatitis $\mathrm{C}$ virus (HCV). However, direct-acting antiviral agents (DAAs) are assuming a more prominent role. At present, only two first-generation DAAs (telaprevir (TVR) and boceprevir (BOC)) are available, although many other candidate DAAs are being developed. TVR and BOC are used only in developed countries to treat patients chronically infected with HCV. They are not used commonly in developing countries because of their high cost.

We can classify DAAs according to their action sites, such as protease inhibitor, polymerase inhibitor, NS5B inhibitor, and NS5A inhibitor. The main mechanism of action of DAAs is the inhibition of enzyme, for example, protease or polymerase, but the NS5A inhibitor has a different mechanism of action from other DAAs. It inhibits the assembly of this replication complex (Table 1) (Figure 1) [1, 2]. Another approach to HCV therapy is to target the host factors that the virus uses for its own life cycle, for example, cyclophilin inhibitors or nitazoxanide. In this paper, we will focus on only DAAs and will not cover other treatment options, like cyclophilin, HCV vaccine. We will discuss the efficacy and limitations of both currently approved and new candidate drugs.

\section{Currently Available DAAs}

In May 2011, the U.S. Food and Drug Administration (FDA) approved TVR and BOC for use in combination therapies with PegIFN- $\alpha$ and RBV for adult patients chronically infected with HCV genotype 1 . The drugs are used to treat patients with compensated liver cirrhosis, who are treatmentnaïve or who have been previously treated with IFN-based regimens $[3,4]$. Both TVR and BOC inhibit the viral NS3/4A serine protease, which is essential for replication $[5,6]$.

2.1. Telaprevir (TVR). Three phase III clinical trials have been conducted to evaluate the efficacy of TVR when administered to treatment-naïve chronic HCV (genotype 1) 
TABLE 1: Characteristics of HCV direct-acting antiviral classes.

\begin{tabular}{|c|c|c|c|c|c|}
\hline Characteristic & Protease inhibitors & Protease inhibitors & $\begin{array}{l}\text { Polymerase } \\
\text { inhibitors }\end{array}$ & $\begin{array}{l}\text { Polymerase } \\
\text { inhibitors }\end{array}$ & $\begin{array}{l}\text { NS5A } \\
\text { inhibitors }\end{array}$ \\
\hline & First generation & Second generation & $\begin{array}{l}\text { Nucleoside } \\
\text { analogs }\end{array}$ & $\begin{array}{l}\text { Non-nucleoside } \\
\text { analogs }\end{array}$ & \\
\hline Potency & $\begin{array}{l}\text { High } \\
\text { Variable among HCV } \\
\text { genotypes }\end{array}$ & $\begin{array}{l}\text { High } \\
\text { Variable }\end{array}$ & $\begin{array}{l}\text { Moderate } \\
\text { Consistent across } \\
\text { genotypes }\end{array}$ & $\begin{array}{l}\text { Variable } \\
\text { Variable among HCV } \\
\text { genotypes }\end{array}$ & $\begin{array}{c}\text { High } \\
\text { Multiple HCV } \\
\text { genotypes }\end{array}$ \\
\hline $\begin{array}{l}\text { Barrier to } \\
\text { resistance }\end{array}$ & Low & Low & High & Very low & Low \\
\hline $\mathrm{PK}$ & $\begin{array}{l}\text { Variable } \\
\text { qd-tid }\end{array}$ & qd & qd & $\begin{array}{l}\text { Variable } \\
\text { qd-tid }\end{array}$ & qd \\
\hline Adverse event & $\begin{array}{l}\text { Rash (SJS, TEN), } \\
\text { anemia, } \\
\text { hyperbilirubinemia } \\
\text { appetite loss, renal } \\
\text { toxicity, elevation of } \\
\text { uric acid }\end{array}$ & $\begin{array}{l}\text { Anemia } \\
\text { hyperbilirubinemia }\end{array}$ & $\begin{array}{l}\text { Mitochondrial nuclear } \\
\text { interaction } \\
(\mathrm{RBV})\end{array}$ & Variable & Variable \\
\hline Drug & $\begin{array}{l}\text { Telaprevir } \\
\text { Boceprevir }\end{array}$ & $\begin{array}{l}\text { Simeprevir } \\
\text { Asunaprevir } \\
\text { Faldaprevir }\end{array}$ & $\begin{array}{l}\text { Sofosbuvir } \\
\text { Mericitabine }\end{array}$ & BMS-791325 & Daclatasvir \\
\hline Clinical trial & $\begin{array}{l}\text { TVR: ADVANCE [7], } \\
\text { ILLUMINATE [8], } \\
\text { REALIZE [9] } \\
\text { BCV: SPRINT-2 [10], } \\
\text { RESPOND-2 [12] }\end{array}$ & $\begin{array}{l}\text { SMV: PILLAR [14], } \\
\text { ASPIRE [15] } \\
\text { ASV: AI447-011 [16] } \\
\text { FDV: SILEN-C2 [17], } \\
\text { SOUND-C2 [18, 19] }\end{array}$ & $\begin{array}{l}\text { SOF: ATOMIC [20], } \\
\text { ELECTRON [21] } \\
\text { MRB: JUMP-C [22], } \\
\text { INFORM-1 [23], } \\
\text { INFORM-SVR [24] }\end{array}$ & & $\begin{array}{c}\text { DCT: } \text { AI447-011 } \\
{[25]}\end{array}$ \\
\hline Comments & & $\begin{array}{l}\text { Better barrier, } \\
\text { pan-genotypic }\end{array}$ & Single target active site & $\begin{array}{l}\text { Allosteric, many } \\
\text { targets }\end{array}$ & $\begin{array}{c}\text { Multiple antiviral } \\
\text { mechanisms of } \\
\text { action }\end{array}$ \\
\hline
\end{tabular}

PK: pharmacokinetics; qd: once a day; tid: three times a day; RBV: ribavirin.

Modified from [1].

SSS: Stevens-Johnson syndrome; TEN: toxic epidermal necrolysis; TVR: telaprevir; BCV: boceprevir; SMV: simeprevir; ASV: asunaprevir; FDV: faldaprevir; SOF: sofosbuvir; MRB: mericitabine; DCV: daclatasvir.

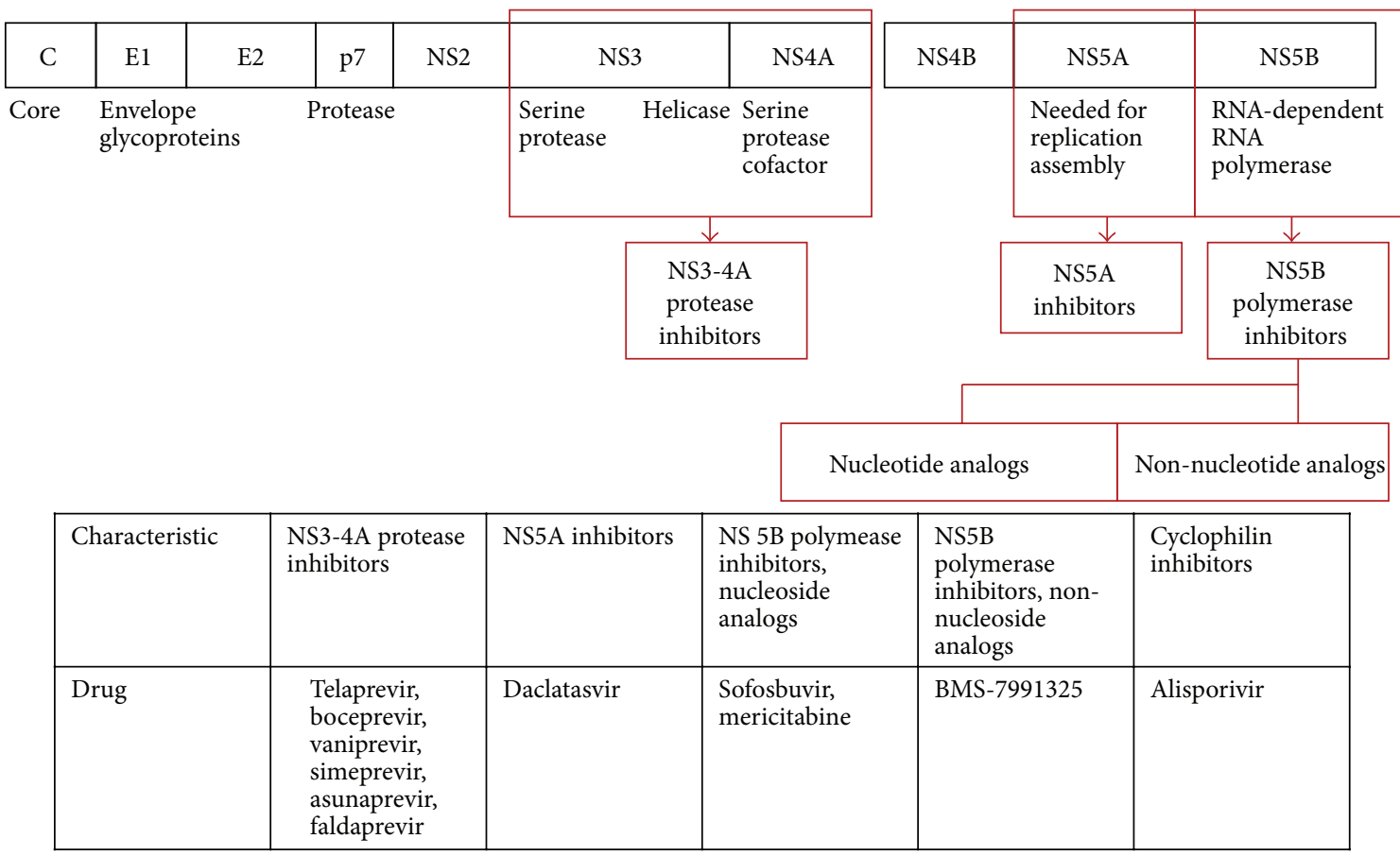

Figure 1: Targets for direct-acting antivirals. Modified from [2]. 
patients in combination with PegIFN- $\alpha-2 \mathrm{a}$ and RBV $[7,8]$. In the ADVANCE trial, patients received TVR together with PegIFN- $\alpha$ and RBV (PR) for either 8 (T8PR) or 12 (T12PR) weeks, followed by PegIFN- $\alpha$ or RBV (PR) alone in a response-guided therapy [7]. Extended rapid virological response (eRVR) was defined as undetectable HCV RNA levels at weeks 4 and 12. The patients who did not achieve an eRVR received PegIFN- $\alpha$ plus RBV for a total of 48 weeks. The overall SVR rates for patients in the T8PR and T12PR groups were $69 \%$ and $75 \%$, respectively. The SVR rate for the control group with only PR was 44\% [7].

The ILLUMINATE, another TVR trial, focused on defining the utility of response-guided therapy (RGT) in patients that did achieve an eRVR. All patients received an initial 12week course of TVR-based triple therapy, followed by treatment with PegIFN- $\alpha$ plus RBV [8]. Patients who achieved an eRVR at week 20 were randomized to receive either an additional 3- or 28-week course of PegIFN- $\alpha$ plus RBV. The overall SVR rate for all patients was $72 \%$. The SVR rates for those patients (65\%) who achieved an eRVR and received either an additional 3- or 28-week course of PegIFN- $\alpha$ plus RBV were $92 \%$ and $88 \%$, respectively.

The REALIZE, the third trial of TVR, was conducted for patients who experienced treatment failure after SOC therapy [9]. The clinical trial had three arms. Patients in the first arm received T12PR triple therapy for 12 weeks, followed by a placebo plus PR for 4 weeks and then PR alone for 32 weeks. The patients in the second arm received placebo plus $\mathrm{PR}$ (lead-in phase) for the first 4 weeks, followed by TVR-based triple therapy for 12 weeks and then PR alone for 32 weeks (48 weeks in total). The patients in the third arm received PR alone for 48 weeks (control group). The overall SVR rates for the three groups were $64 \%, 66 \%$, and $17 \%$, respectively. The best response rate was observed for those patients in each group that had previously relapsed after PR therapy (83\%, $88 \%$, and $24 \%$, resp.) [9].

In summary, the triple regimen including TVR showed good response in genotype 1 patients. The SVR rate can be maximized using a response-guided paradigm. The triple regimen was also effective in treatment-failure patients, especially who relapsed after PR therapy.

2.2. Boceprevir. Let us look at two important phase III clinical trials on BOC. The first one, SPRINT-2, evaluated the efficacy of BOC in two cohorts of treatment-naïve patients [10]. All patients were first treated with a lead-in therapy comprising PegIFN- $\alpha$-2b plus weight-based RBV for a period of 4 weeks, followed by one of three regimens. After the lead-in, patients were assigned to one of three groups. (1) Group 1, PegIFN- $\alpha$ 2b, RBV, and placebo for an additional 44 weeks. (2) Group 2 , BOC, PegIFN- $\alpha-2 b$, and RBV for an additional 24 weeks, followed by 20 more weeks of PegIFN- $\alpha-2 b$ if HCV RNA was detectable at weeks 8 and 24. (3) Group 3, BOC, PegIFN- $\alpha$ $2 \mathrm{~b}$, and RBV for an additional 44 weeks, that is, SOC therapy (Figure 2) [11]. The overall SVR rates were higher in the BOCtreated arms (63\% and 66\%) than in the SOC arm (38\%), but differed according to race. In black patients, the SVR rates were $42 \%$ in the RGT arm, 53\% in the fixed duration arm, and $23 \%$ in the SOC arm.
The RESPOND-2 trial was a phase III clinical trial [12]. The subjects were prior partial responders or relapsers with PegIFN- $\alpha-2 b$ and RBV. Null responders were not studied in this trial. (1) Group 1, PegIFN- $\alpha-2 b, \mathrm{RBV}$, and placebo for an additional 44 weeks. (2) Group 2, BOC, PegIFN- $\alpha$-2b, and RBV for an additional 32 weeks, followed by 12 more weeks of PegIFN- $\alpha-2 b$ and RBV if HCV RNA was detectable at week 8, but undetectable at week 12. (3) Group 3, BOC, PegIFN- $\alpha-2 b$, and RBV for an additional 44 weeks. Therapy was discontinued in patients who were HCV RNA positive at week 12 (Figure 2) [11]. The overall SVR rates at week 24 were $21 \%, 59 \%$, and $66 \%$, respectively in Group 1, Group 2 (RGT), and Group 3 (48 weeks). These triple therapy appear to yield even higher rates of SVR, 29, 69, and 75\% in prior relapsers than in partial responders $(7 \%, 40 \%$, and $50 \%)$.

2.3. Vaniprevir (MK-7009). Vaniprevir is a macrocyclic hepatitis $\mathrm{C}$ virus nonstructural protein $3 / 4 \mathrm{~A}$ protease inhibitor. Treatment-naïve patients with $\mathrm{HCV}$ genotype 1 infection were randomized to receive open-label PegIFN and RBV in combination with blinded placebo or vaniprevir $(300 \mathrm{mg}$ bid, $600 \mathrm{mg}$ bid, $600 \mathrm{mg} \mathrm{qd}$, and $800 \mathrm{mg}$ qd) for 28 days, and then open-label PegIFN and RBV for an additional 44 weeks. Across all doses, vaniprevir was associated with $\mathrm{HCV}$ RNA levels approximately $3 \log _{10} \mathrm{IU} / \mathrm{mL}$ lower in vaniprevirtreated patients, compared to placebo recipients. Rates of RVR were significantly higher in each of the vaniprevir dose groups, compared to the control regimen $(68.8 \%-83.3 \%$ versus $5.6 \%$; $P<0.001$ for all comparisons). Vomiting appeared to be more common at higher vaniprevir doses $(40 \%$ in $600 \mathrm{mg}$ bid group) [13].

\subsection{Preliminary Data from Patients with Other Genotypes Treated with DAAs}

2.4.1. HCV Genotype 2. The SVR rate for patients infected with HCV genotype 2 and treated with SOC is almost $80 \%$. There is no space for DAAs to show any increase of treatment effect because it is enough high. DAAs may be less effective in this patient group than in patients infected with HCV genotype 1 . TVR, the first agent to directly target viral replication, is effective against HCV-2 but not against HCV-3 (see below). Foster et al. evaluated combined treatment with TVR plus PegIFN- $\alpha-2 \mathrm{a}$ and RBV in five patients infected with HCV-2 and compared the results with those obtained after treating nine patients with TVR alone or treating nine patients with PR (control group). Triple combination therapy yielded an SVR rate of $100 \%$, which is remarkable considering the $89 \%$ rate observed in patients receiving standard PR [26]. Other NS3/4A protease inhibitors, nucleoside and non-nucleoside reverse replicase inhibitors, and NS5A inhibitors have antiviral activity against HCV-2. One of the most promising drugs is a nucleotide analogue polymerase inhibitor called PSI-7977 [27]. An open-label study (the PROTON study) evaluated the efficacy of PSI-7977 in 15 patients infected with HCV2 , in 10 patients infected with $\mathrm{HCV}-3$, and in a larger group of patients with HCV-1 infection [28]. That study reported an RVR of $96 \%$ after the triple combination of $400 \mathrm{mg}$ of 


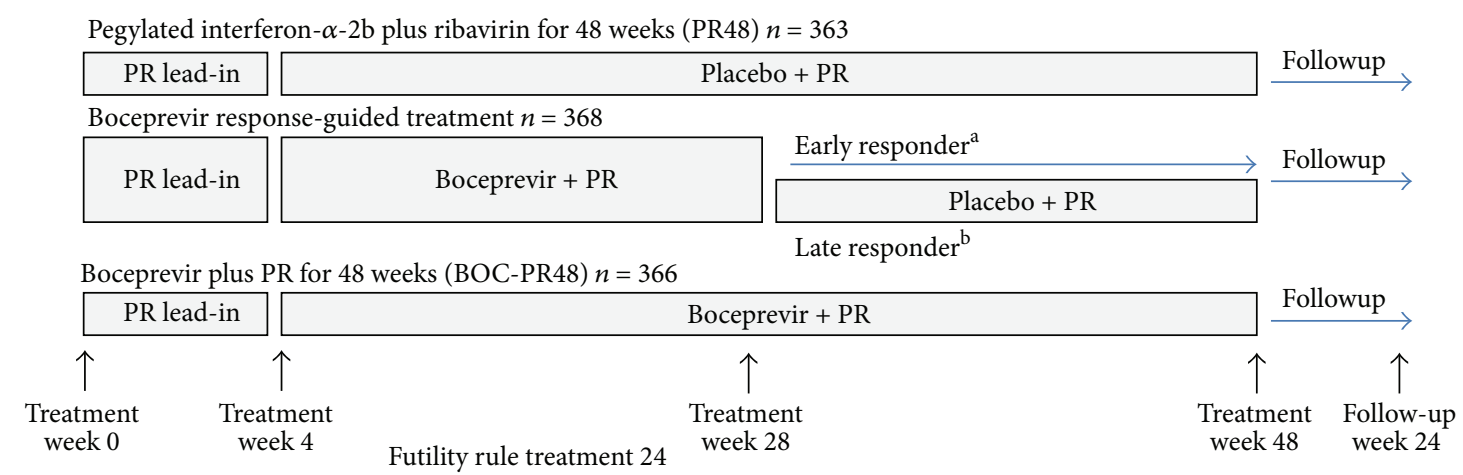

(a) SPRINT-2

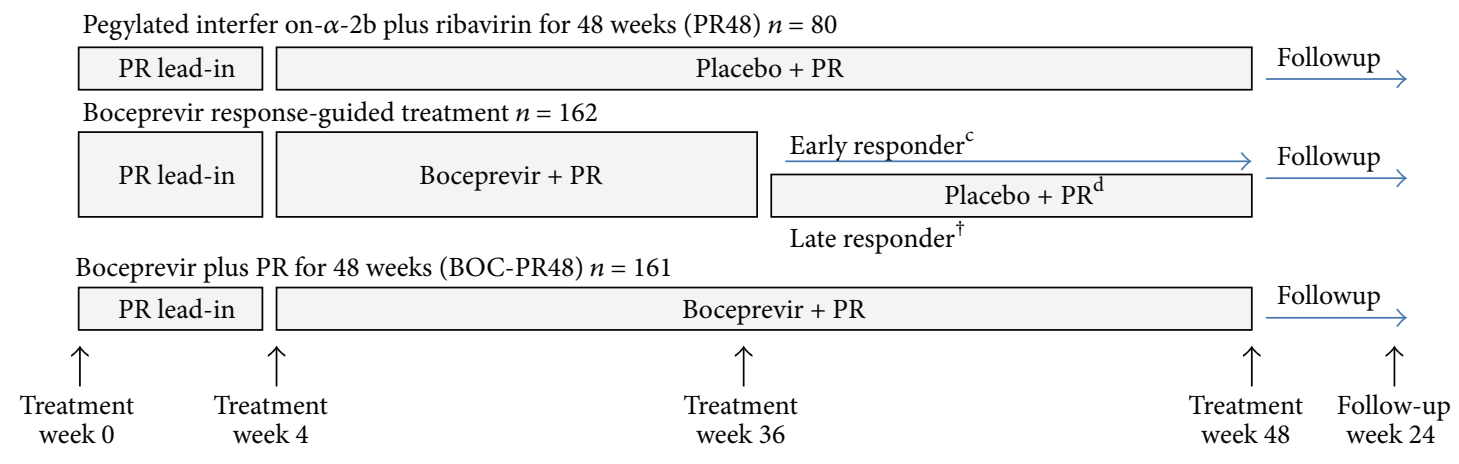

Futility rule treatment 12

(b) RESPOND-2

FIGURE 2: Phase III trials of boceprevir in patients with hepatitis C genotype-1 infection. (a) SPRINT-2 trial in previously untreated patients. (b) RESPOND-2 trial for previously treated patients; patients were partial responders and relapsers and null-responders. PR: pegylated interferon$\alpha$-2b $1.5 \mu \mathrm{g} / \mathrm{kg}$ per week plus weight-based ribavirin $600-1400 \mathrm{mg}$ per day. BOC: boceprevir $800 \mathrm{mg}$ every $8 \mathrm{~h} .{ }^{\mathrm{a}} \mathrm{Hepatitis} \mathrm{C}$ RNA treatment weeks 8-24 undetectable. ${ }^{\mathrm{b}}$ Hepatitis C RNA treatment week 8 detectable, treatment week 24 undetectable. ${ }^{\mathrm{c}}$ Hepatitis C RNA treatment weeks 8-12 undetectable. ${ }^{\mathrm{d}}$ Hepatitis C RNA treatment week 8 detectable, treatment week 12 undetectable. Excerpted from Pearlman [11].

PSI-7977 plus PR. Twenty-four HCV-2 and HCV-3 patients who completed the 12 weeks of treatment achieved SVR (96\%).

2.4.2. HCV Genotype 3. The SVR rate for patients infected with HCV genotype 3 and treated with SOC is almost $80 \%$ [29]. TVR and BOC have revolutionized the treatment of genotype $1 \mathrm{HCV}$. Indeed, both have recently been recommended for use in combination with standard $\mathrm{PR}$ regimen for the treatment of patients chronically infected with $\mathrm{HCV}$ genotype 1 . However, both BOC and TVR are ineffective against $\mathrm{HCV}-3$.

2.5. Future Therapeutic Options. Two available DAAs, TVR and BOC, have several limitations. The role of these drugs is a supplement to PegIFN. These two drugs can cause severe side effects, for example, anemia, rash, and hyperbilirubinemia. Lastly, their dosing schedule is three times a day. The therapeutic drugs that are being developed for future use try to resolve these limitations of currently available DAAs. These new drugs fall into three categories: second-wave protease inhibitors, second-generation protease inhibitors, and polymerase inhibitors.
2.5.1. Second-Wave Protease Inhibitors. Second-wave protease inhibitors offer several advantages over currently available drugs. In the near future, improved pharmacokinetics will allow a once-a-day dosing schedule, which means that the side-effect profiles should be more tolerable. Second-wave protease inhibitors have similar genotype coverage and similar resistance profiles to those of TVR and BOC and will replace the first-generation protease inhibitors currently used for PR combination therapy, thereby becoming the initial partners in the first generation of "all-oral regimens."

Simeprevir (TMC435) is an NS3/4A protease inhibitor that is taken orally once per day; the drug is currently undergoing phase III clinical trials for the treatment of HCV infection [30]. The PILLAR study (a phase IIb trial) was designed to test the efficacy of simeprevir when used in combination with PR for either 24 or 48 weeks. An SVR was achieved in $68-76 \%$ of patients treated with this triple therapy regimen, and approximately $80 \%$ of subjects were eligible to receive shortened 24 weeks of therapy. The result of subgroup analysis was very high SVR (93-96\%) [14]. Adverse effects were similar to those observed after SOC therapy. The lowest rate of relapse $(8 \%)$ was found in the study arm receiving TMC 435 (150 mg/day) plus PR for 24 weeks. 
The ASPIRE trial was a phase IIb trial for genotype 1 patients who had failed previous treatment with PR therapy. All patients received PR for 48 weeks. The best results were observed in the group treated with triple therapy with simeprevir $150 \mathrm{mg}$ (SVR) plus PR in comparison with placebo plus PR, which achieved an SVR of $85 \%$ versus $37 \%$ in prior relapsers, $75 \%$ versus $9 \%$ in partial responders, and $51 \%$ versus $19 \%$ in prior nonresponders [15].

Faldaprevir (BI201335) is another NS3/4A protease inhibitor that has completed phase II testing (the SILENC1 study) and can be administered using a once-per-day dosing schedule. The treatment regimen included BI201335 in addition to PR for 24 weeks at doses of 120 and $240 \mathrm{mg}$, followed by another 24 weeks of standard therapy [17]. The overall SVR rate was $83 \%$ for the $240 \mathrm{mg}$ dose. Ninetytwo percent of the patients that showed an eRVR also achieved an SVR, regardless of the duration of subsequent PR therapy. Adverse events (mostly gastrointestinal) meant that treatment was discontinued in $7.3 \%$ of subjects.

Asunaprevir (BMS-650032) is a twice-daily protease inhibitor that is being developed for use with daclatasvir (an NS5A inhibitor) and BMS 791325 (a non-nucleoside inhibitor) in both IFN-containing and IFN-free regimens. Asunaprevir plus daclatasvir was the first regimen to cure HCV-infected patients without the need for IFN [16]. However, asunaprevir is not an ideal protease inhibitor because a twice-per-day schedule may be associated with hepatotoxicity.

\subsubsection{Second-Generation Protease Inhibitors. Two second-} generation protease inhibitors, MK-5172 and ACH-2684, are currently under clinical trial.

MK-5172 is a novel macrocyclic NS3/4a protease inhibitor that is currently undergoing phase II clinical trials. R155 is the main overlapping position for drug resistance, and different mutations at this site within the NS3 protease confer resistance to nearly all protease inhibitors. However, MK-5172 shows potent antiviral activity against $\mathrm{HCV}$ viruses harboring mutations at position R155. Based on its preclinical profile, MK-5172 is expected to have broad-spectrum activity against multiple HCV genotypes (including genotype 3) and other clinically important drug-resistant variants. Indeed, trials in genotype-1-positive patients show that $75 \%$ had HCV RNA levels below the limit of detection. In addition, the drug was generally well tolerated [31].

ACH-2684 is a macrocyclic, noncovalent, reversible inhibitor of the NS3 protease. Phase Ib clinical trials showed that administration of ACH-2684 to patients infected with $\mathrm{HCV}$ genotype 1 achieved a mean $3.73 \log _{10}$ reduction in HCV RNA levels after 3 days of monotherapy at a single dose of $400 \mathrm{mg} /$ day. In addition, ACH-2684 was safe and well tolerated [32]. Thus, this drug shows great promise, although further clinical trials are needed.

2.5.3. Polymerase Inhibitor-Nucleoside Inhibitors. Two HCV nucleos(t)ide analogues have entered phase II/III clinical trials: mericitabine and sofosbuvir.
2.5.4. Nucleoside Inhibitors in Clinical Trials with Interferon. Mericitabine (RG 7128): the JUMP-C trial (phase II) investigated the safety and efficacy of mericitabine (RG 7128) (1000 mg bid) plus PR after 24 weeks of response-guided therapy. The overall SVR rates were higher in patients treated with mericitabine plus PR than in patients treated with PR alone (58\% versus 36\%) [22].

Sofosbuvir (GS-7977): the ATOMIC study (another phase II trial) evaluated combined treatment with sofosbuvir plus PR in 316 noncirrhotic patients infected with HCV genotypes 1 , 4, or 6. This study evaluated the proper duration of treatment for genotype 1 patient. Patients infected with $\mathrm{HCV}$ genotype 1 were randomized into two groups: one group received sofosbuvir plus PegIFN/RBV for 12 or 24 weeks, and the other received sofosbuvir plus PR for 12 or 24 weeks, followed by rerandomization $(1: 1)$ into two further groups that received either an additional 12 weeks of sofosbuvir alone or an additional 12 weeks of sofosbuvir plus RBV. The results of an interim analysis showed that patients who received 12 weeks of therapy with the triple combination of sofosbuvir plus PR achieved SVR rates of 90\% [20].

2.5.5. Nucleoside Inhibitors in Clinical Trials without Interferon. Mericitabine (RG 7128): the INFORM-1 study provided the first proof of principle that combined treatment with mericitabine plus danoprevir (an NS3/4 protease inhibitor) in the absence of IFN is effective at reducing HCV RNA levels. At day 14, the highest combined dose (1000 mg mericitabine and $900 \mathrm{mg}$ danoprevir bid) resulted in a median $-5.1 \log _{10} \mathrm{IU} / \mathrm{mL}$ reduction in HCV RNA levels in treatment-naïve patients and a median $-4.9 \log _{10} \mathrm{IU} / \mathrm{mL}$ reduction in HCV RNA levels in patients that did not respond to previous PR therapy [23].

The INFORM-SVR trial (a phase IIb trial) evaluated the efficacy of a 12- or 24-week interferon-free regimen comprising ritonavir-boosted danoprevir (DNV/r, $100 \mathrm{mg} / 100 \mathrm{mg}$ ) plus mericitabine (1000 mg, bid), either with or without RBV, in treatment-naïve patients infected with HCV genotype 1. The data showed that $71 \%$ of the patients infected with $\mathrm{HCV}$ genotype $1 \mathrm{~b}$ who received 24 weeks of $\mathrm{DNV} / \mathrm{r}$, mericitabine, and RBV achieved an SVR; however, only $26 \%$ of patients infected with genotype la achieved an SVR. Higher SVR rates were reported in patients who were rapid virological responders [24].

Sofosbuvir (GS-7977/PSI-7977): the ELECTRON trial evaluated the efficacy of sofosbuvir plus RBV in the absence of IFN. The results showed that treatment-naïve patients infected with HCV genotypes 2 or 3 achieved an SVR rate of $100 \%$. In addition, patients infected with HCV genotype 1 , who did not respond to previous treatment with $\mathrm{PR}$, received sofosbuvir plus RBV for 12 weeks; however, $89 \%$ of patients relapsed after the end of treatment [21].

2.5.6. Interferon-Free Combination Trials. The SOUND-C2 study (faldaprevir plus BI 207127, with or without RBV): the Sound-C2 study is an open-label, randomized, phase IIb study of 362 treatment-naïve patients infected with HCV genotype 1 who were allocated to one of five treatment 


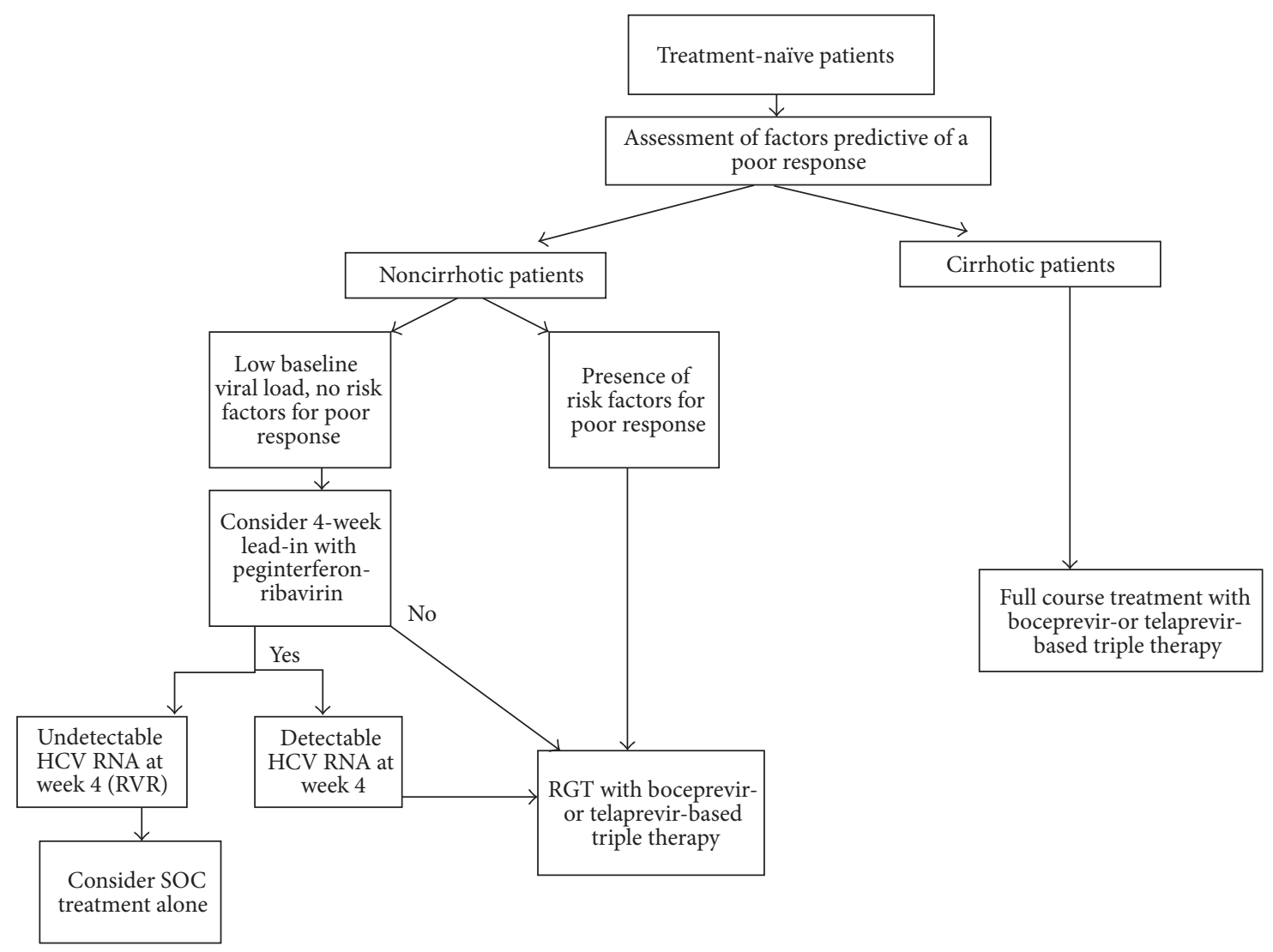

FIGURE 3: Proposed algorithm for the use of protease inhibitors in treatment-naïve HCV genotype 1 infected patients. Pretreatment assessment should include careful consideration of lifestyle factors, comorbid conditions, potential drug interactions, and assessment for the presence of cirrhosis. In noncirrhotic patients, the presence of factors predictive of a poor response to therapy should be patients with no risk factors for a poor response to therapy; the decision to use a 4-week lead-in with peginterferon and ribavirin and to continue on SOC in those who achieve an RVR should only be taken following careful and balanced discussion with the patient. Excerpted from Ramachandrean et al. [35].

arms [18]. The final results showed that up to $85 \%$ of $\mathrm{HCV}$ patients infected with genotype $1 \mathrm{~b}$ achieved an SVR. The optimal regimen was 28 weeks of faldaprevir (120 mg once daily), and BI 207127 (600 mg bid). The overall SVR rate was $70 \%$, compared with $85 \%$ in the prevalent genotype- $1 \mathrm{~b}$ patient subgroup [19].

The Aviator study (ABT-450/r, ABT-267, or ABT-333 plus RBV): the Aviator phase IIb study assessed the safety and efficacy of ABT-450/r, ABT-267, or ABT-333 plus RBV (administered for 8,12 , or 24 weeks) in noncirrhotic treatmentnaïve patients and in patients who did not respond to previous treatment with PR [33]. The SVR in treatmentnaïve patients infected with genotype $1 \mathrm{HCV}$ was $97.5 \%$ after 12 weeks, whereas the SVR in PR nonresponders infected with genotype 1 was $93.3 \%$. Treatment-naïve patients infected with genotype la achieved an SVR of $96 \%$ after 12 weeks, whereas PR nonresponders achieved an SVR of $89 \%$. For those patients infected with genotype $1 \mathrm{~b}$, the SVR was $100 \%$ for both treatment-naïve and PR nonresponders.

Daclatasvir plus sofosbuvir with or without RBV: this trial was designed to test the efficacy of combined treatment with daclatasvir plus sofosbuvir against $\mathrm{HCV}$ genotypes 1, 2, and 3.
Daclatasvir plus sofosbuvir were administered, either with or without RBV, for 12 or 24 weeks and either with or without a 7-day run-in with sofosbuvir [34]. A total of 44 patients infected with genotypes 2 or $3 \mathrm{HCV}$ were enrolled in three arms: one arm comprised a 7-day run-in with sofosbuvir followed by 23 weeks of daclatasvir plus sofosbuvir; another arm comprised daclatasvir plus sofosbuvir for 24 weeks; and the other comprised daclatasvir plus sofosbuvir plus RBV for 24 weeks. Eighty-eight percent of patients in the first group achieved an SVR at week 12, compared with $100 \%$ in the second group and $86 \%$ in the third group.

Daclatasvir, asunaprevir, and BMS-791325: daclatasvir is the first NS5A replication complex inhibitor to be investigated in HCV clinical trials and is currently in phase III of development. Asunaprevir is an NS3 protease inhibitor that is also undergoing phase III development along with daclatasvir. BMS-791325 is a non-nucleoside inhibitor of the NS5B polymerase and is currently undergoing phase II development as a component of daclatasvir-based treatment regimens. This phase II study examined the efficacy of these DAAs in HCV G1 treatment-naïve patients [25]. The trial split patients into two groups. Group 1 received a 24-week course 


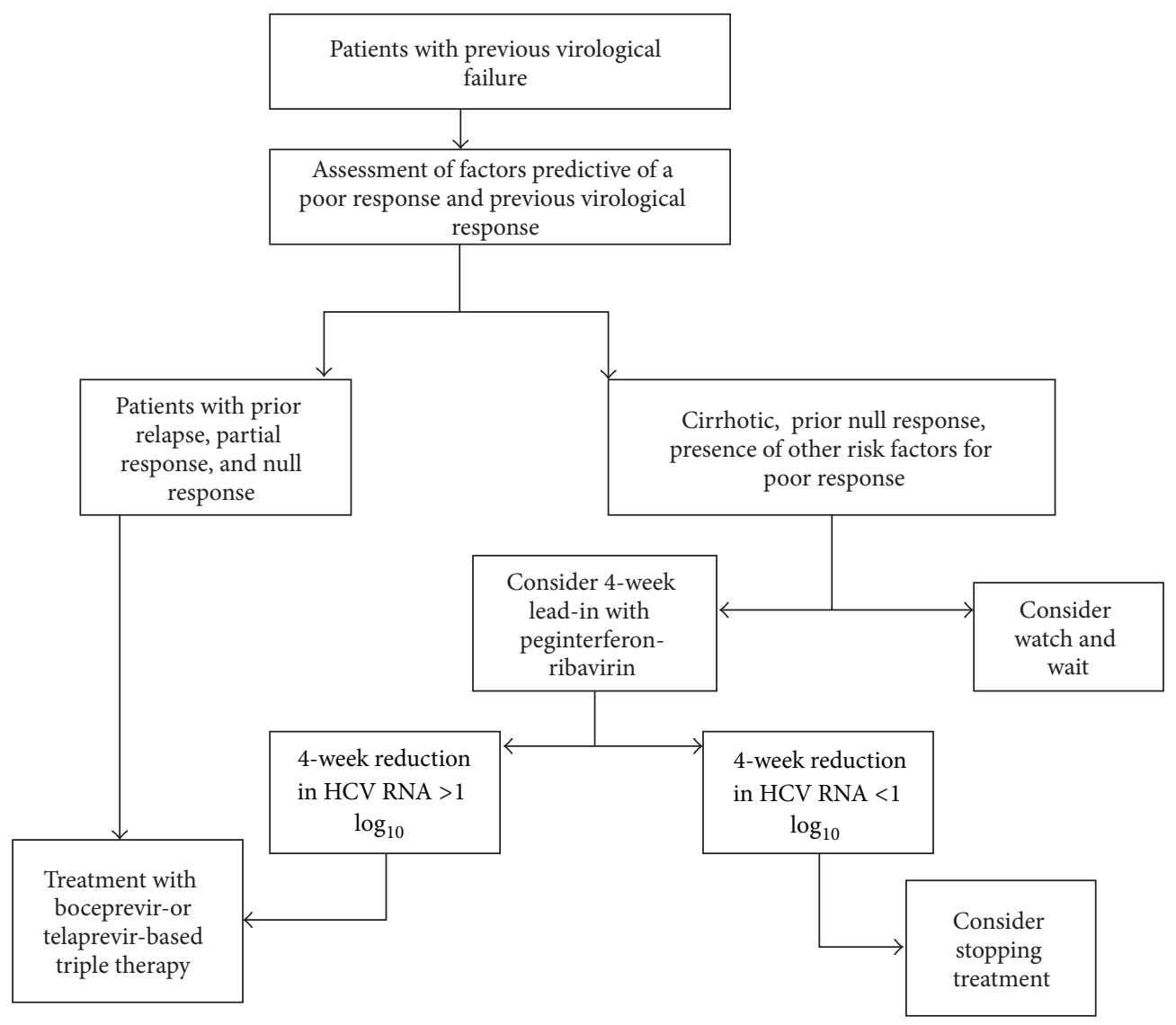

FIGURE 4: Proposed algorithm for the use of protease inhibitors in HCV genotype 1 infected patients who have had previous virological failure on treatment. Pretreatment assessment should include careful consideration of lifestyle factors, comorbid conditions, potential drug interactions, assessment for the presence of cirrhosis, and the presence of factors predictive of a poor response to therapy. Identification of the degree of previous response should be attempted. If this information is not available, patients should be considered as prior null responders to maximize cure rates. In cirrhotic prior null responders, the decision to watch and wait for novel therapies or to use a 4-week lead-in with peginterferon and ribavirin to identify patients more likely to achieve an SVR should only be taken following careful and balanced discussion with the patient. Excerpted from Ramachandrean et al. [35].

of daclatasvir, asunaprevir, and BMS-79132. Group 2 received a 12-week course of daclatasvir, asunaprevir, and BMS-79132. The result was that $94 \%$ of patients showed an undetectable viral load at week 4 and at the end of the trial in Group 1. One hundred percent of patients had an undetectable viral load at the end of the trial in group 2.

2.6. Optimized Treatment Algorithms for the Management of HCV Patients. This paper did not focus on general approaches for treating patients that are chronically infected with HCV. Instead, it focused on treatments based on DAAs and particularly on clinical trials of DAAs that target HCV genotype 1 . HCV genotypes 2 and 3 can be effectively treated with current SOC therapy. Genotype 4 is the most difficult genotype to treat. The standard treatment for HCV genotype 4 is a 48 -week course of PR. Furthermore, patients infected with HCV genotype 4 who have previously relapsed, or are non-responders, are unlikely be cured by the $\mathrm{PR}$ regimen. The optimized treatment algorithms are shown in Figures 3 and 4 [35].

\section{Conclusion}

In conclusion, only two DAAs have been approved for the treatment of patients infected with HCV (TVR and BOC). Both are used in combination with PR therapy. Although several clinical trials examined the efficacy of IFN-free regimens (to avoid the side effects associated with IFN), most clinical trials have examined the efficacy of DAAs when used in combination with IFN. Response-guided therapy using the PegIFN- $\alpha$ regimen can be used with DAA therapy to select nonresponders. TVR and BOC play an important role in the treatment of patients chronically infected with $\mathrm{HCV}$ genotype 1 . Genotypes 2 and 3 (but not genotype 4) can be effectively treated with SOC therapy. Of the emerging second-generation treatments, a triple regimen containing sofosbuvir shows great promise in terms of treatment efficacy. In addition, the combination of two oral drugs (daclatasvir and asunaprevir) achieved a high SVR rate (95\%). Another oral drug combination (mericitabine and danoprevir) was examined in the INFORM study and achieved an SVR rate of $71 \%$. Thus, future regimens may not require the use of IFN 
injections. Drug resistance will become a problem in the field of chronic HCV research; however, current data suggest that it is not yet a significant factor.

\section{Authors' Contribution}

Hee Bok Chae acquired the data and wrote the paper. Seon Mee Park consulted a direction of the paper. Sei Jin Youn performed proofreading and critical revision.

\section{Acknowledgments}

This work was supported by a Chungbuk National University grant, 2012. Dr. Chae is a member of the advisory committee for both BMS Korea and Gilead Korea.

\section{References}

[1] C. A. Stedman, "Current prospects for interferon-free treatment of hepatitis C in 2012," Journal of Gastroenterology and Hepatology, vol. 28, pp. 38-45, 2013.

[2] B. McGovern, B. Abu Dayyeh, and R. T. Chung, "Avoiding therapeutic pitfalls: the rational use of specifically targeted agents against hepatitis C infection," Hepatology, vol. 48, pp. 1700-1712, 2008.

[3] U.S Food and Drug Administration. FDA news release. FDA approves Incivek for hepatitis C, May 2011, http:// www.fda.gov/NewsEvents/Newsroom/PressAnnouncements/ ucm256299.htm.

[4] U.S Food and Drug Administration. FDA news release. FDA approves Incivek for hepatitis C, May 2011, http:// www.fda.gov/NewsEvents/Newsroom/PressAnnouncements/ ucm 255390.htm.

[5] Vectrelis (boceprevir) capsules. Merck. May 2011, http://www .accessdata.fda.gov/drugsatfda_docs/label/2011/202258lbl.pdf.

[6] Incibek (telaprevir) film coated tablets. Vertex. May 2011, http:// www.accessdata.fda.gov/drugsatfda_docs/label/2011/201917lbl .pdf.

[7] I. M. Jacobson, J. G. McHutchison, G. Dusheiko et al., “Telaprevir for previously untreated chronic hepatitis C virus infection," New England Journal of Medicine, vol. 364, no. 25, pp. 24052416, 2011.

[8] K. E. Sherman, S. L. Flamm, N. H. Afdhal et al., "Responseguided telaprevir combination treatment for hepatitis $\mathrm{C}$ virus infection," New England Journal of Medicine, vol. 365, no. 11, pp. 1014-1024, 2011.

[9] S. Zeuzem, P. Andreone, S. Pol et al., "Telaprevir for retreatment of HCV infection," New England Journal of Medicine, vol. 364, no. 25, pp. 2417-2428, 2011.

[10] F. Poordad, J. McCone, B. R. Bacon et al., "Boceprevir for untreated chronic HCV genotype 1 infection," New England Journal of Medicine, vol. 364, no. 13, pp. 1195-1206, 2011.

[11] B. L. Pearlman, "Protease inhibitors for the treatment of chronic hepatitis C genotype-1 infection: the new standard of care," Lancet Infectious Diseases, vol. 12, pp. 717-728, 2012.

[12] B. R. Bacon, S. C. Gordon, E. Lawitz et al., "Boceprevir for previously treated chronic HCV genotype 1 infection," New England Journal of Medicine, vol. 364, no. 13, pp. 1207-1217, 2011.

[13] M. P. Manns, E. Gane, M. Rodriguez-Torres et al., "Vaniprevir with pegylated interferon alpha-2a and ribavirin in treatmentnaïve patients with chronic hepatitis $\mathrm{C}$ : a randomized phase II study," Hepatology, vol. 56, no. 3, pp. 884-893, 2012.
[14] M. Fried, M. Buti, G. J. Dore et al., “TMC435 in combination with peginterferon and ribavirin in treatment naive $\mathrm{HCV}$ genotype 1 patients: final analysis of the PILLAR phase II b study," in Proceedings of the 62nd Annual Meetgin of the American Assoication for the Study of Liver Diseases, Abstract LB-5, San Francisco, Calif, USA, November 2011.

[15] O. Lenz, B. Fevery, L. Vijgen et al., "TMC 435 in patients infected with $\mathrm{HCV}$ genotype 1 who have failed previous pegylated interferon/ribavirin treatment: virologic analysis of the ASPIRE trial," in Proceedings of the 47th Annual Meeting of the European Association for the Study of the Liver, Abstract 9, Barcelona, Spain, April 2010.

[16] A. S. Lok, D. F. Gardiner, E. Lawitz et al., "Preliminary study of two antiviral agents for hepatitis C genotype 1," New England Journal of Medicine, vol. 366, no. 3, pp. 216-224, 2012.

[17] M. S. Sulkowski, T. Asselah, P. Ferenci et al., "Treatment with the 2nd generation HCV PI BI 201335 results in high and consistent SVR rates-results from SILEN-C1 in treatment naïve patients across different baseline factors," Hepatology, vol. 54, supplement, p. 473A, 2011.

[18] S. Zeuzem, V. Soriano, T. Asselah et al., "Interferon (IFN)-free combination treatment with HCV NS3/4A protease inhibitor BI 201335 and the non-nucleoside NS5B inhibitor BI 207127 +/- ribavirin (R): final results of SOUND-C2 and predictors of response," Hepatology, vol. 56, supplement, pp. 308A-309A, 2012.

[19] S. Zeuzem, T. Asselah, P. Angus et al., "Efficacy of the protease inhibitor BI 201335, polymerase inhibitor BI 207127, and ribavirin in patients with chronic HCV infection," Gastroenterology, vol. 141, no. 6, pp. 2047-2055, 2011.

[20] T. Hassanein, E. Lawitz, I. Crespo et al., "Once daily sofosbuvir (GS-7977) plus PEG/RBV: high early response rates are maintained during post-treatment follow-up in treatmentnaïve patients with $\mathrm{HCV}$ genotype 1,4, and 6 infection in the ATOMIC study," Hepatology, vol. 56, supplement, p. 307A, 2012.

[21] E. J. Gane, C. A. Stedman, R. H. Hyland et al., "Once daily GS7977 plus ribavirin in HCV genotype 1-3: the ELECTRON," Hepatology, vol. 56, supplement, pp. 306-37A, 2012.

[22] P. Pockros, D. Jensen, N. Tsai et al., "SVR-12 among G1/4 treatment-naive patients receiving mericitabine in combination with peg-IFNa-2A7RBV: interim analysis from the JUMP-C study," Journal of Hepatology, vol. 56, supplement, pp. 477-478, 2012.

[23] E. J. Gane, S. K. Roberts, C. A. M. Stedman et al., "Oral combination therapy with a nucleoside polymerase inhibitor (RG7128) and danoprevir for chronic hepatitis C genotype 1 infection (INFORM-1): a randomised, double-blind, placebocontrolled, dose-escalation trial," The Lancet, vol. 376, no. 9751, pp. 1467-1475, 2010.

[24] E. J. Gane, "Interferon-free treatment with a combination of merivitabine and danoprevir/ $\mathrm{r}$ with or without ribavirin in treatment naïve HCV genotype 1 infected patients," Journal of Hepatology, vol. 56, supplement, pp. 555-556, 2012.

[25] G. T. Everson, K. D. Sims, M. Rodriguez-Torres et al., "An interferon-free, ribavirin-free 12-week regimen of daclatasvir (DCV), asunaprevir (ADV), and BMS-791325 yielded SVR4 of $94 \%$ in treatment-naïe paeitns with genotype(GT) 1 chronic hepatitis C viru (HCV) infection," Hepatology, vol. 56, supplement, p. LB3, 2012.

[26] G. R. Foster, C. Hezode, J. P. Bronowicki et al., "Telaprevir alone or with peginterferon and ribavirin reduces HCV RNA in patients with chronic genotype 2 but not genotype 3 infections," Gastroenterology, vol. 141, no. 3, pp. 881-889, 2011. 
[27] Pharmasset Inc, "Pharmasset announces the expansion of the ELECTRON trial in chronic hepatitis C," Press release. June 2011.

[28] J. Lalezari, E. Lawitz, M. Rodriguez-Torres et al., "Once daily PSI-7977 PegIFN/RBV in a phase 2b trial: rapid virologic suppression in treatment-naive patients with G2/G3," Journal of Hepatology, vol. 54, p. s28, 2011.

[29] A. Andriulli, A. Mangia, A. Iacobellis, A. Ippolito, G. Leandro, and S. Zeuzem, "Meta-analysis: the outcome of anti-viral therapy in HCV genotype 2 and genotype 3 infected patients with chronic hepatitis," Alimentary Pharmacology and Therapeutics, vol. 28, no. 4, pp. 397-404, 2008.

[30] M. Manns, H. Reesink, T. Berg et al., "Rapid viral response of once-daily TMC435 plus pegylated interferon/ribavirin in hepatitis C genotype-1 patients: a randomized trial," Antiviral Therapy, vol. 16, no. 7, pp. 1021-1033, 2011.

[31] V. Summa, S. W. Ludmerer, J. A. McCauley, C. Fandozzi, C. Burlein, G. Claudio et al., "MK-5172, a selective inhibitor of hepatitis $\mathrm{C}$ virus NS3/4a protease with broad activity across genotypes and resistant variants," Antimicrobial Agents and Chemotherapy, vol. 56, no. 8, pp. 4161-4167, 2012.

[32] M. Huang, S. Podos, D. Patel et al., "ACH-2684: HCV NS3 protease inhibitor with potent activity against multiple genotypes and known resistant variants," Hepatology, vol. 52, supplement, p. 1204A, 2010.

[33] K. V. Kowdley, E. Lawitz, F. Poordad et al., "A 12-week interferon-free treatment regimen with ABT-450/r, ABT-267, ABT-333 and ribavirin achieves SVR rates (observed data) of $99 \%$ in treatment-naïve patients and $93 \%$ in prior null responders with HCV genotype 1 infection," Hepatology, vol. 56, supplement, p. LB1, 2012.

[34] M. S. Sulkowski, D. F. Gardiner, M. Rodriguez-Torres et al., "High rate of sustained virologic response with the all-oral combination fo daclatasvir (NS5A inhibitor) plus sofosbuvir (nucleotide NS5B inhibitor), with or without ribavirin, in treatment-naïve paeitns chronically infected with HCV genotype 1,2, or 3," Hepatology, vol. 56, supplement, p. LB2, 2012.

[35] P. Ramanchandran, A. Fraser, K. Agrawal et al., "UK consensus guidelines for the use of the protease inhibitors boceprevir and telaprevir in genotype 1 chronic hepatitis C infected patients," Alimentary Pharmacology \&Therapeutics, vol. 35, pp. 647-662, 2012. 


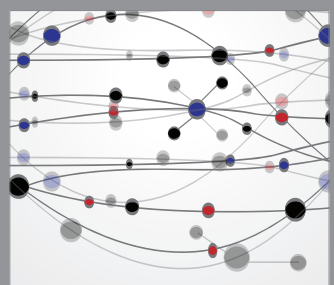

The Scientific World Journal
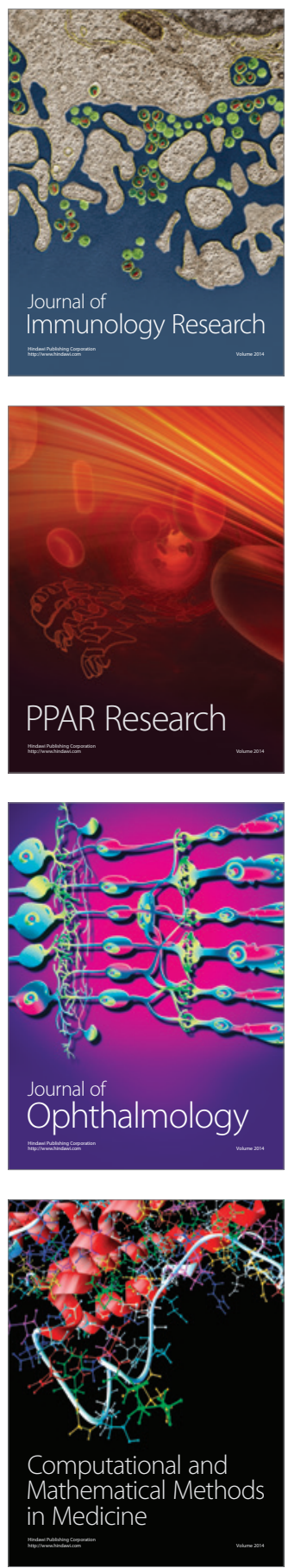

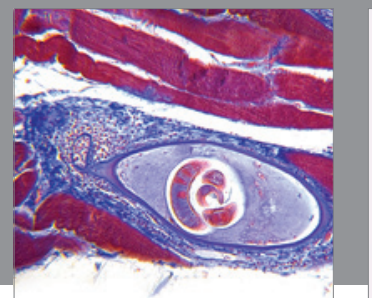

Gastroenterology

Research and Practice
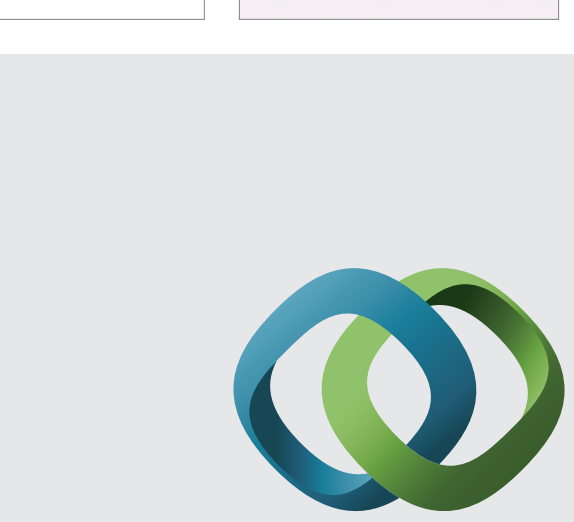

\section{Hindawi}

Submit your manuscripts at

http://www.hindawi.com
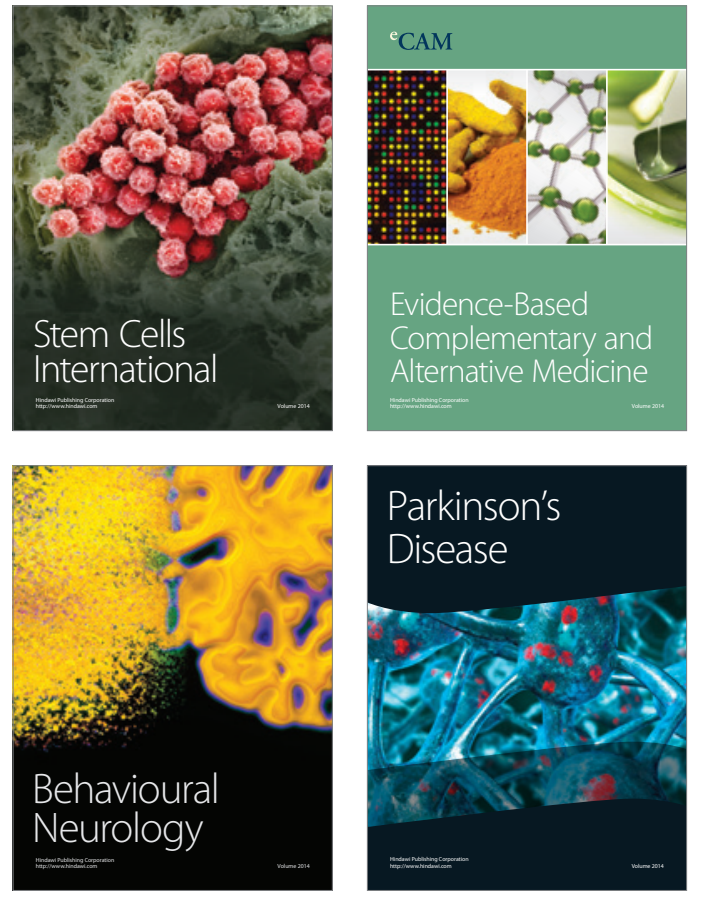
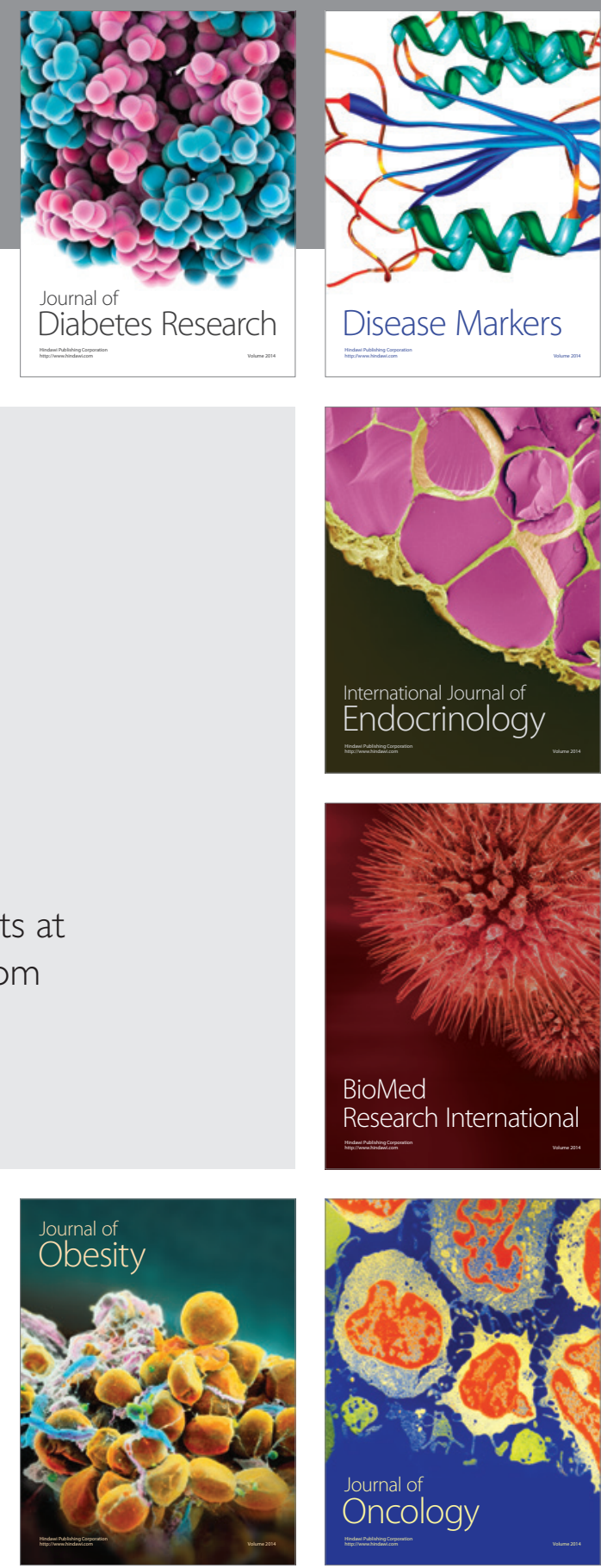

Disease Markers
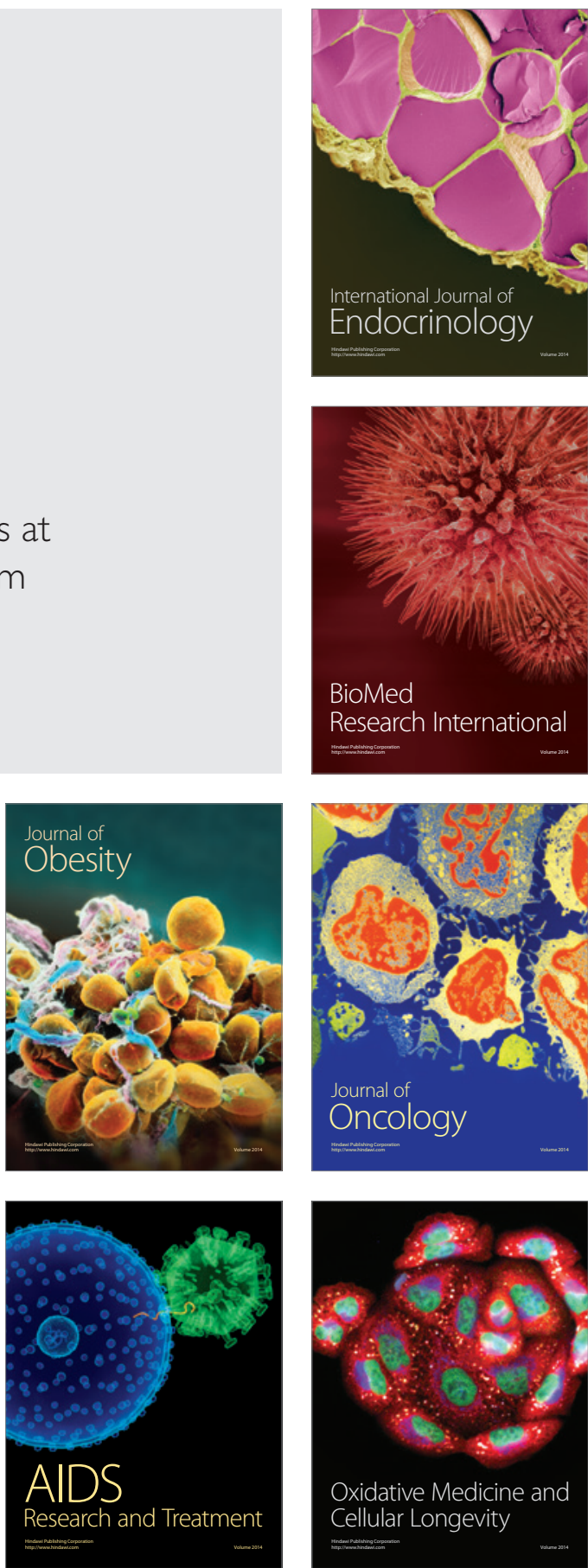